\title{
The protective effects of $\beta$-sitosterol and vermicularin from Thamnolia vermicularis (Sw.) Ach. against skin aging in vitro
}

\author{
HAIYUAN YU ${ }^{1}$, XUEQING SHEN ${ }^{1}$, DAN LIU $^{2}$, MINHUA HONG ${ }^{2}$ and YANHUA LU ${ }^{1}$ \\ ${ }^{1}$ State Key Laboratory of Bioreactor Engineering, East China University of Science and \\ Technology, 130 Meilong Road, 200237 Shanghai, People's Republic of China \\ ${ }^{2}$ Technology Center, Shanghai Inoherb Cosmetics limited company, 121 Chengyin \\ Road, 200083 Shanghai, People's Republic of China \\ Manuscript received on October 18, 2018; accepted for publication on December 27, 2018
}

\begin{abstract}
How to cite: YU H, SHEN X, LIU D, HONG M AND LU Y. 2019. The protective effects of $\beta$-sitosterol and vermicularin from Thamnolia vermicularis (Sw.) Ach. against skin aging in vitro. An Acad Bras Cienc 91: e20181088. DOI 10.1590/0001-3765201920181088.

Abstract: Aged skin, featured with dryness and wrinkles, has received mounting attention due to its adverse influences on beauty. $\beta$-Sitosterol and vermicularin are two common active ingredients of Thamnolia vermicularis (Sw.) Ach., a traditional Chinese medicine, of which the anti-aging effect has been discovered. Their protective performance against skin aging was assayed by co-culturing with skin cells in this work. Results showed that $\beta$-sitosterol promoted the biosynthesis of hyaluronic acid by increasing the expression of hyaluronic acid synthases in fibroblasts and enhanced the expression of skin barrier functional proteins including aquaporin 3, loricrin, filaggrin and involucrin in keratinocytes, which conduced to the moisture retention within skin. Moreover, vermicularin might function as an anti-wrinkle agent by preventing the loss of collagen type I. Specifically, vermicularin reduced the amount of reactive oxygen species within hydrogen-peroxide-induced fibroblasts; together with suppressing the activation of mitogen-activated protein kinases, it could inhibit the production of matrix metalloproteinases- 1 . The present research will contribute to the development of the compounds as anti-aging ingredients for future applications in cosmetic formulations and functional food as well as promote further studies of raw materials containing alike compounds.
\end{abstract}

Key words: anti-wrinkle, moisturize, $\beta$-sitosterol, skin aging, Thamnolia vermicularis (Sw.) Ach., vermicularin.

\section{INTRODUCTION}

Aging is a spontaneous and inescapable process during biological development. The outermost organ of the body, skin can be subjected to various

Correspondence to: Yanhua Lu

E-mail: luyanhua@ecust.edu.cn

ORCid: https://orcid.org/0000-0003-1338-4149

Minhua Hong

E-mail: hongmh@inoherb.com

ORCid: https://orcid.org/0000-0002-5937-917X internal and external causes of aging (Tobin 2017, Farage et al. 2008). Moreover, skin changes such as dryness, sagging and wrinkles are commonly observed as the most apparent characteristics of body aging (Zouboulis and Makrantonaki 2011).

Skin dryness results primarily from the loss of moisture-retaining substances and epidermal barrier dysfunction (Hashizume 2004, Tončić et al. 2018). Hyaluronic acid (HA) is remarkable for its unique ability to hold water within dermis, 
while aquaporin3 (AQP3) and cornified envelope proteins including loricrin (LOR), filaggrin (FLG) and involucrin (IVL) are important due to their contributions to skin barrier function and moisture loss inhibition in epidermis (Papakonstantinou et al. 2012, Kim et al. 2018, Averbeck et al. 2007). Therefore, HA and skin barrier functional proteins are main focuses of the research in skin dryness treatment.

A crucial factor upon skin sagging and wrinkling is the loss of collagen type I (COL-I)the most abundant collagen in dermal connective tissues, and the overexpression of matrix metalloproteinase 1 (MMP-1) (also known as collagenase) is recognized as a vital inducement (Tobin 2017, Contet-Audonneau et al. 1999, FreitasRodríguez et al. 2017). Therefore, regulating the contents of COL-I and MMP-1 is an effective strategy for wrinkling prevention. It is known that oxidative stress serves as the molecular mechanism of skin aging (Lephart 2016). Excess of reactive oxygen species (ROS) can damage oxidatively the biomacromolecules and meanwhile cause MMP1 overexpression via mitogen-activated protein kinases (MAPK) signaling pathway (Kammeyer and Luiten 2015). Given that hydrogen peroxide $\left(\mathrm{H}_{2} \mathrm{O}_{2}\right)$ can irritate the overproduction of ROS, it functions as an active pressure source of aging inducement in dermal fibroblasts (Wen et al. 2017).

Growing concerns about skin health lead consumers to prefer cosmetic products that contain functional ingredients. Natural plants account for an important source of functional cosmetic additives (Juhász et al. 2018). Lichen Thamnolia vermicularis (Sw.) Ach., a traditional Chinese herbal medicine, has been proved by modern scientific researches to perform multiple pharmacological activities, such as antioxidant, anti-inflammatory, radio-resistance, etc. (Luo et al. 2006, Crawford 2015). Furthermore, the anti-aging function of $T$. vermicularis extract on human dermal fibroblasts has been reported by Chen et al. (2017). Nevertheless, the specific effective components in $T$. vermicularis extract (TV) along with the underlying mechanisms of skin aging await more in-depth investigations.

A phenolic acid and also the characteristic component in TV, vermicularin (Verm) exists in $T$. vermicularis at a high content (Guo et al. 2011). Equally representative is $\beta$-sitosterol (Sito), the most abundant plant sterol in the human diet (Lomenick et al. 2015). In this study, the antiaging effects of Sito and Verm were investigated by detecting their biological activities against skin drying and wrinkling in cultured human skin fibroblasts and keratinocytes.

\section{MATERIALS AND METHODS}

\section{MATERIALS}

TV was provided by Shanghai Inoherb Co., Ltd (Shanghai, China). Sito standard substance was purchased from PureOne Biotechnology (Shanghai, China). Human dermal fibroblast-adult (HDF) and human permanent epidermal cell ( $\mathrm{HaCaT})$ were purchased from ScienCell Research Laboratories (San Diego, CA, USA). Human COL-I ELISA kits were purchased from Shanghai MLBIO Biotechnology (Shanghai, China). ELISA kits for Human MMP-1, Human HA, Human AQP3 and Human LOR were purchased from ExCell Biotech (Shanghai, China). Primary antibodies againstERK, phosphorylated ERK (p-ERK), phosphorylated JNK (p-JNK) and phosphorylated p38 MAPK (pp38), and HRP-conjugated secondary antibodies were from Signalway Antibody (SAB, MD, USA). Primary antibodies against JNK, p38 MAPK, HAS1 and GAPDH were from Proteintech (Chicago, USA). INV, HAS2 and HAS3 antibodies were purchased from ABclonal Technology (Wuhan, China). Antibody against FLG was from Wanleibio (Shenyang, China). Other chemical reagents without special description were from Sinopharm Chemical Reagent (Shanghai, China). 


\section{ISOLATION OF SITO AND VERM}

TV was dissolved in 50\% methanol and separated by silica-column chromatography (200 mesh). Sito (yield 2.5\%) was separated from methanol stream by preparative reversed-phase high performance liquid chromatography using a C18 column (20 x $250 \mathrm{~mm}, 10 \mathrm{~mm}$; Shimadzu, Kyoto, Japan) and identified by HPLC (Agilent 1100) and MS ((+) ESI-TOF: $437.2 \mathrm{M}+\mathrm{Na}^{+}$) (showed as Figures $\mathrm{S} 1, \mathrm{~S} 2$ in Supplementary Material). Verm (yield $16.7 \%$ ) was isolated from ethyl acetate stream by recrystallization purification and identified with MS ((-) ESI-TOF: $\left.375.1 \mathrm{M}-\mathrm{H}^{+}\right)$and ${ }^{1} \mathrm{H}$ NMR $\left(\mathrm{CDCl}_{3}, 400 \mathrm{MHz}\right)(\delta \mathrm{H}: 10.32(1 \mathrm{H}, \mathrm{s}, \mathrm{CHO}), 6.53$ (1H, s, H-2'), 6.35 (1H, s, H-5), 4.17 (3H, s, OCH3), 2.54 (3H, s, Me-8), 2.24 (3H, s, Me-9')) (showed as Figures S3, S4). The chemical structures of Sito and Verm (Fig. 1a) were consistent with literature (Ma and Chen 2001).

\section{CELLS CULTURE}

The HDF and HaCaT were both cultured in Dulbecco's Modified Eagle Medium (DMEM) containing 10\% (v/v) fetal bovine serum (FBS) (ExCell Bio, Shanghai, China) in an incubator (Sanyo, Osaka, Japan) with humidified atmosphere and $5 \% \mathrm{CO}_{2}$ at $37{ }^{\circ} \mathrm{C}$. HDF cells within 10 generations were used for experiments.

\section{MTT ASSAY}

Effects of compounds on cell viability of HDF and $\mathrm{HaCaT}$ were detected via MTT assay. Cells $\left(1 \times 10^{5}\right.$ cells $\left./ \mathrm{mL}\right)$ were inoculated in 96 -well plate and allowed to adhere for $12 \mathrm{~h}$. HDF and HaCaT were treated with different concentrations of drugs (TV at $12.5-100 \mu \mathrm{g} / \mathrm{mL}$, Sito at $12.5-100$ $\mu \mathrm{M}$ and Verm at $12.5-100 \mu \mathrm{M}$ ) for 48 and $24 \mathrm{~h}$, respectively. Then, cells were co-cultured with 0.5 $\mathrm{mg} / \mathrm{mL}$ MTT (Biotech well, Shanghai, China) for $4 \mathrm{~h}$, and the formazan was dissolved with dimethyl sulfoxide. The absorbance at $570 \mathrm{~nm}$ was detected by a microplate reader (SpectraMax i3; Molecular Devices, Sunnyvale, CA, USA).

$\mathrm{H}_{2} \mathrm{O}_{2}$ IRRITATION AND SAMPLES TREATMENT IN

$\mathrm{H}_{2} \mathrm{O}_{2}$-induced HDFs were performed as described previously with minor modifications (Zhou et al. 2014). Briefly, HDF cells $\left(2 \times 10^{5}\right.$ cells $\left./ \mathrm{mL}\right)$ were inoculated and allowed to adhere for $12 \mathrm{~h}$. Then, cells were treated with compounds for $24 \mathrm{~h}$ and coincubated with $\mathrm{H}_{2} \mathrm{O}_{2}$ (at the final concentration of $200 \mu \mathrm{M}$ ) for another $24 \mathrm{~h}$ to induce oxidative stress. The HDF cells incubated in fresh DMEM served as control group ( $\mathrm{Ctrl}$ ) and the HDF cells treated only with $200 \mu \mathrm{M} \mathrm{H}_{2} \mathrm{O}_{2}$ served as the oxidative stress control $\left(\mathrm{H}_{2} \mathrm{O}_{2}\right)$.

\section{ELISA ANALYSIS}

HDF cells $\left(2 \times 10^{5}\right.$ cells $\left./ \mathrm{mL}\right)$ were inoculated in 96well plates. After treatment with compounds for $24 \mathrm{~h}$, cells were stimulated or non-stimulated with $\mathrm{H}_{2} \mathrm{O}_{2}$. Cells culture supernatants were harvested and evaluated the levels of HA, COL-I and MMP-1 by commercially available ELISA kits.

HaCaT cells $\left(2 \times 10^{5}\right.$ cells $\left./ \mathrm{mL}\right)$ were inoculated in 6-well plates and treated with compounds. Then, cells were rinsed with precooling phosphate buffer solution (PBS) and lysed using cell lysis buffer (Biotech well, Shanghai, China). The lysates were performed human AQP3 and LOR assay by ELISA. The levels of target proteins were normalized to total proteins that quantified with a BCA kit (Biotech well, Shanghai, China).

\section{QUANTITATIVE REAL-TIME POLYMERASE CHAIN REACTION (QRT-PCR)}

HDF or $\mathrm{HaCaT}$ cells $\left(2 \times 10^{5}\right.$ cells $\left./ \mathrm{mL}\right)$ were inoculated in 6-well plates. After $24 \mathrm{~h}$ of treatment, cells were rinsed twice with precooling PBS. Total RNA of the cells was extracted with a total RNA isolation kit (KeyGEN, Nanjing, China). And then a reverse transcription kit (Takara, Shiga, 
Japan) was used to obtain cDNA. SYBR realtime fluorescent quantitative polymerase chain reaction was performed using $2 \times$ RealStar Green Fast Mixture (Genstar, Beijing, China). The qRTPCR reaction was conducted with a program as follows: pre-denaturation at $95{ }^{\circ} \mathrm{C}$ for $30 \mathrm{~s}$, then forty cycles of $95{ }^{\circ} \mathrm{C}$ for $5 \mathrm{~s}, 60^{\circ} \mathrm{C}$ for $30 \mathrm{~s}, 72{ }^{\circ} \mathrm{C}$ for $1 \mathrm{~min}$. The expression levels of target genes were conducted by $\Delta \Delta \mathrm{C}_{\mathrm{T}}$ method and normalized to GAPDH. The sequences of primers were as follow: HAS1: 5'-GCG ATA CTG GGT AGC CTT CA3' (forward), 5'-GGT TGT ACC AGG CCT CAA GA-3' (reverse); HAS2: 5' - CCT CAT CAT CCA AAG CCT GT -3' (forward), 5'- AAA CAG TTG CCC TTT GCA TC -3' (reverse); HAS3: 5'- GTC ATG TAC ACG GCC TTC AA -3' (forward), 5'CCT ACT TGG GGA TCC TCC TC -3' (reverse); HYAL1: 5'- GTG CTG CCC TAT GTC CAG AT -3' (forward), 5' - ATT TTC CCA GCT CAC CCA GA -3' (reverse); HYAL2: 5'- TCT ACC ATT GGC GAG AGT G -3' (forward), 5'- AGC AGC CGT GTC AGG TAA T -3' (reverse); HYAL3: 5'CCT CCA GTG CCC TCT TCC -3' (forward), 5'CTG TCC CAG GAT GAC CTT GT -3' (reverse); AQP3: 5'- CAT CTA CAC CCT GGC ACA GA -3' (forward), 5'- GGC TGT GCC TAT GAA CTG GT -3' (reverse); LOR: 5'- CAT GAT GCT ACC CGA GGT TT -3' (forward), 5'- ACT GGG GTT GGG AGG TAG TT -3' (reverse); IVL: 5'- GTG GGG GAG AGA GGG AAT TA -3' (forward), 5'- CTC ACC TGA GGT TGG GAT TG -3' (reverse); FLG: 5'- GTT ACA ATT CCA ATC CTG TTG TTT TC -3' (forward), 5'- CGT TGC ATA ATA CCT TGG ATG ATC -3' (reverse); GAPDH: 5'- TCC ACT GGC GTC TTC ACC -3' (forward), 5' - GGC AGA GAT GAT GAC CCT TTT -3 ' (reverse).

\section{MEASUREMENT OF INTRACELLULAR ROS LEVEL}

Intracellular ROS level was monitored by a ROS assay kit (KeyGEN, Nanjing, China). Briefly, HDF cells were inoculated in 6-well plates and treated with compounds and $\mathrm{H}_{2} \mathrm{O}_{2}$. Then, cells were stained with $10 \mu \mathrm{M}$ DCFH-DA at $37{ }^{\circ} \mathrm{C}$ for $20 \mathrm{~min}$. The cells were harvested by trypsinization and the fluorescence intensity ( $\lambda$ excitation $=485$ $\mathrm{nm}, \lambda$ emission $=525 \mathrm{~nm}$ ) was determined using a microplate reader (SpectraMax i3; Molecular Devices, Sunnyvale, CA, USA).

\section{WESTERN BLOT ANALYSIS}

HDF cells were inoculated and incubated with compounds and $\mathrm{H}_{2} \mathrm{O}_{2}$. HaCaT cells were treated with compounds only. The cells were rinsed by PBS and lysed using cell lysis buffer with PMSF and Phosphatase Inhibitor cocktail (Biotech well, Shanghai, China) in ice-bath. The total proteins extracted were quantified using a BCA kit. The mixtures of protein samples $(20 \mu \mathrm{g})$ and loading buffer were boiled and separated by $10 \%$ sodium dodecyl sulfate-polyacrylamide gel electrophoresis (SDS-PAGE). Then protein bands in the gel were transferred to PVDF membrane (Millipore, MA, USA), followed by blocking with 5\% BSA and incubation with primary antibodies and HRPconjugated secondary antibodies. The protein bands were visualized by ECL luminescence reagent (Biotech well, Shanghai, China) via biological image analysis system (FR-1800, Furi Co., Ltd, Shanghai, China).

\section{STATISTICAL ANALYSIS}

Experiments were performed independently at least three times. The data were expressed as the mean \pm SD and analyzed using SPSS program (V22.0, IBM Co., NY, USA). The statistical differences between groups were analyzed via one-way analysis of variance (ANOVA) and $P<0.05$ was considered significant.

\section{RESULTS}

EFFECTS OF TV, SITO AND VERM ON CELL VIABILITY OF HDF AND HACAT

The cytotoxicity of TV, Sito and Verm towards $\mathrm{HDF}$ and $\mathrm{HaCaT}$ was determined with MTT assay. $\mathrm{TV}$ at $0-50 \mu \mathrm{g} / \mathrm{mL}$, Sito at $0-25 \mu \mathrm{M}$ and Verm at 

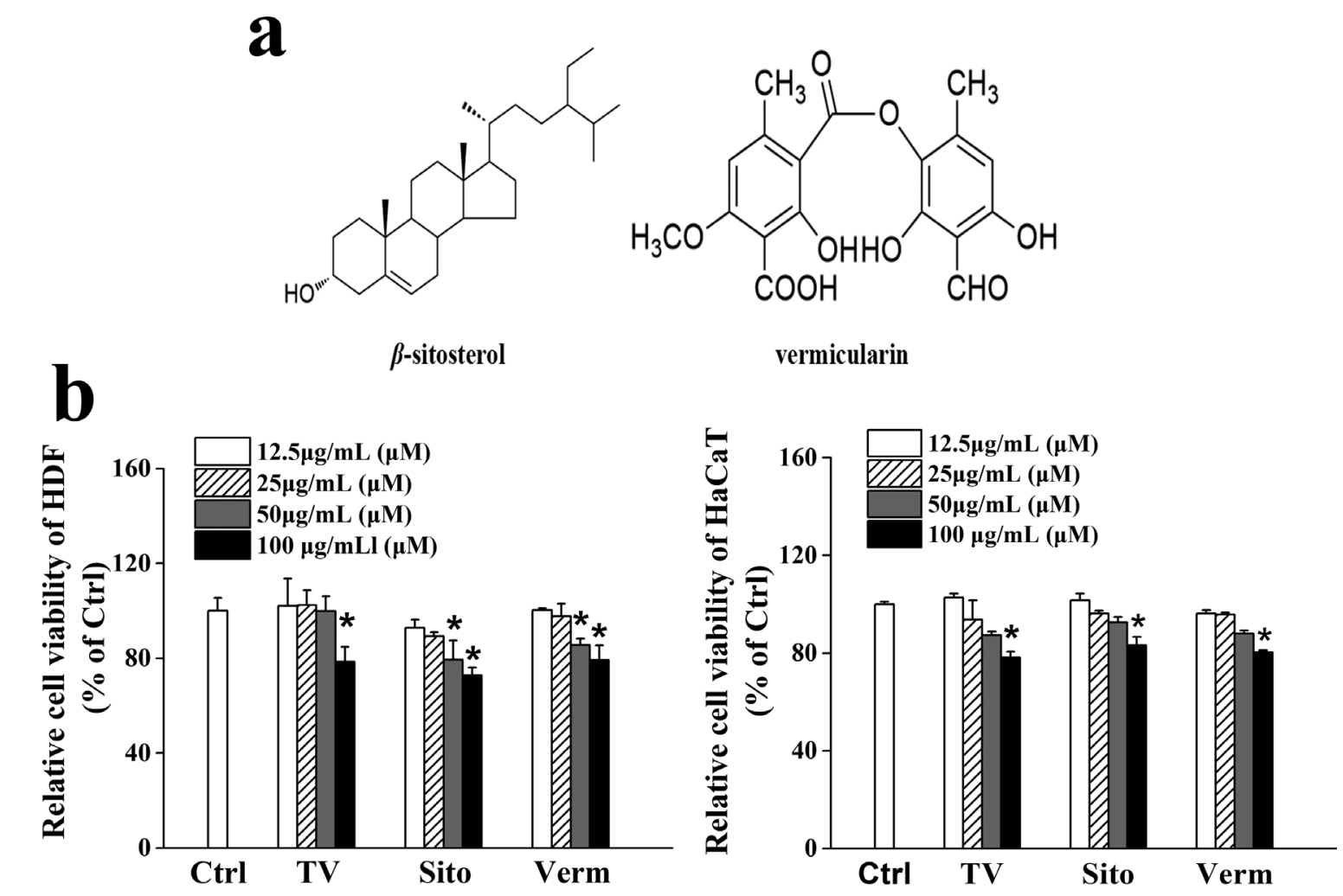

Figure 1 - Structures of $\beta$-sitosterol and vermicularin (a) and their effects on cell viability of HDF and $\mathrm{HaCaT}(\mathbf{b}){ }^{*} P<$ 0.05 vs. Ctrl group.

$0-25 \mu \mathrm{M}$ barely influenced $\mathrm{HDF}$ viability, and TV at $0-50 \mu \mathrm{g} / \mathrm{mL}$, Sito at 0-50 $\mu \mathrm{M}$ and Verm at 0-50 $\mu \mathrm{M}$ exerted negligible effects on $\mathrm{HaCaT}$ viability (Fig. 1b). Compounds at as-designated concentrations were not cytotoxic and thus applied in subsequent experiments.

\section{SITO-PROMOTED HA PRODUCTION VIA UP- REGULATING HAS AND DOWN-REGULATING HYAL IN HDF}

As a measure of moisturizing capacity of compounds, HA production in HDF cells was assessed by ELISA, with nacetylglucosamine (GlcNAc) the HA precursor taken as a positive control. Results showed that Sito improved effectively the HA secretion in a does-dependent manner and by $18 \%$ at high concentration, while Verm hardly altered the level of HA (Fig. 2a, b).

In order to clarify the specific mechanism of Sito promoting HA secretion, the expression of hyaluronic acid synthases (HAS1, -2, -3) and hyaluronidases (HYAL1, -2, -3) in HDF was further investigated. According to the measurements, Sito does-dependently increased the mRNA and protein levels of HAS1, -2, -3 (Fig. 2c, e), whereas a decrement in HYAL3 mRNA level was observed as the concentration of Sito reached $25 \mu \mathrm{M}$ (Fig. 2d).

SITO PROMOTED THE EXPRESSION OF AQP3, LOR, FLG AND IVL IN HACAT

For exploring effects of compounds on epidermal barrier function, the protein levels of AQP3 and LOR were measured by ELISA and the levels of FLG and IVL were measured by western blot. Alltrans retinoic acid (ATRA) or calcium chloride $\left(\mathrm{CaCl}_{2}\right)$ was taken as the positive control promoting the expression of target protein (Bellemère et al. 2008, Pleguezuelos and Kapas 2006). Sito outperformed remarkably Verm in increasing the protein levels of AQP3 and LOR (Fig. 3a, b). 

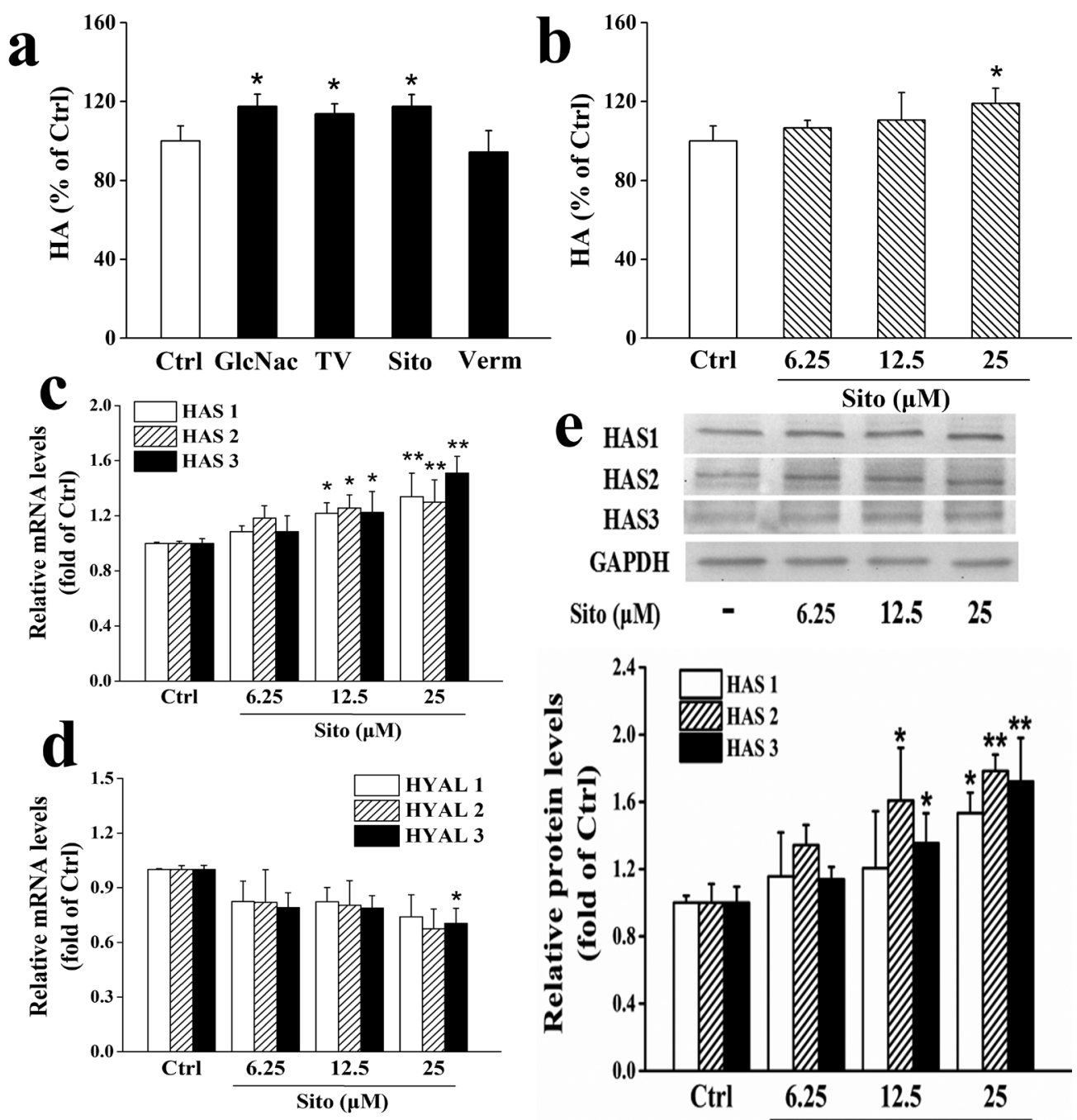

GAPDH
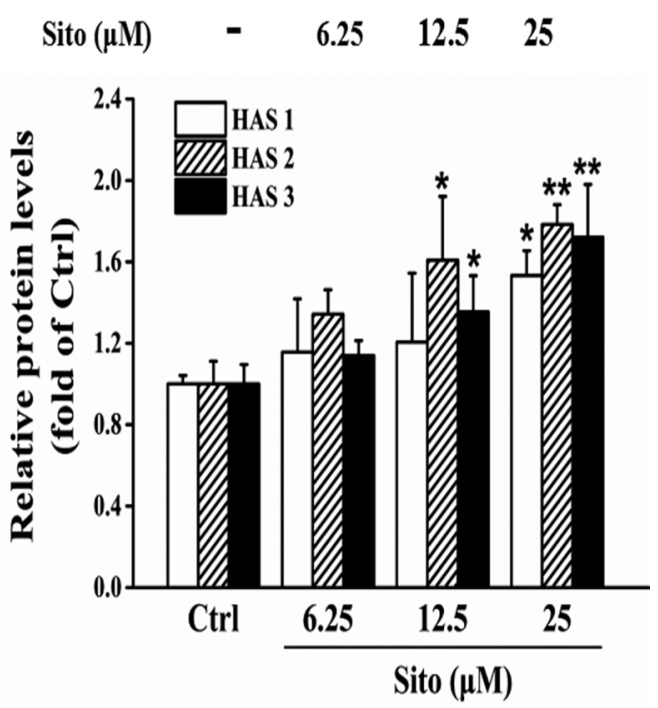

Figure 2 - Effects of compounds on HA content and on the expression of HASs and HYALs in HDF. Amount of HA (a, b) was measured by ELISA kit. The mRNA expression of HAS1-3 (c) and HYAL1-3 (d) was measured by qRT-PCR. The protein expression of HAS1-3 (e) was measured by western blot. * $P<0.05$ vs. Ctrl group.

Furthermore, Sito significantly enhanced the mRNA and protein levels of AQP3, LOR, FLG and IVL in a does dependent manner (Fig. 3c-f).

\section{VERM-INCREASED THE CONTENT OF COL-I} BY DECREASING MMP-1 PRODUCTION VIA SUPPRESSING ROS LEVEL AND MAPK SIGNALING IN HDF

As an evaluation of compounds' anti-wrinkle effects, their influences on the contents of COL-I, MMP-1 and ROS were determined with $\mathrm{H}_{2} \mathrm{O}_{2}$ - induced HDF. Nicotinamide (VB3) or ascorbic acid (VC) was taken as the positive control (Chen and Damian 2014). The level of COL-I decreased by $23 \%$ and the levels of MMP-1 and ROS increased respectively by $36 \%$ and $55 \%$ in $\mathrm{H}_{2} \mathrm{O}_{2}$-induced HDF (Fig. 4a-c). Results indicated that Verm increased surprisingly the content of COL-I and also decreased effectively the levels of MMP-1 and ROS, while Sito hardly regulated these factors (Fig. 4). Moreover, Verm restored the levels 

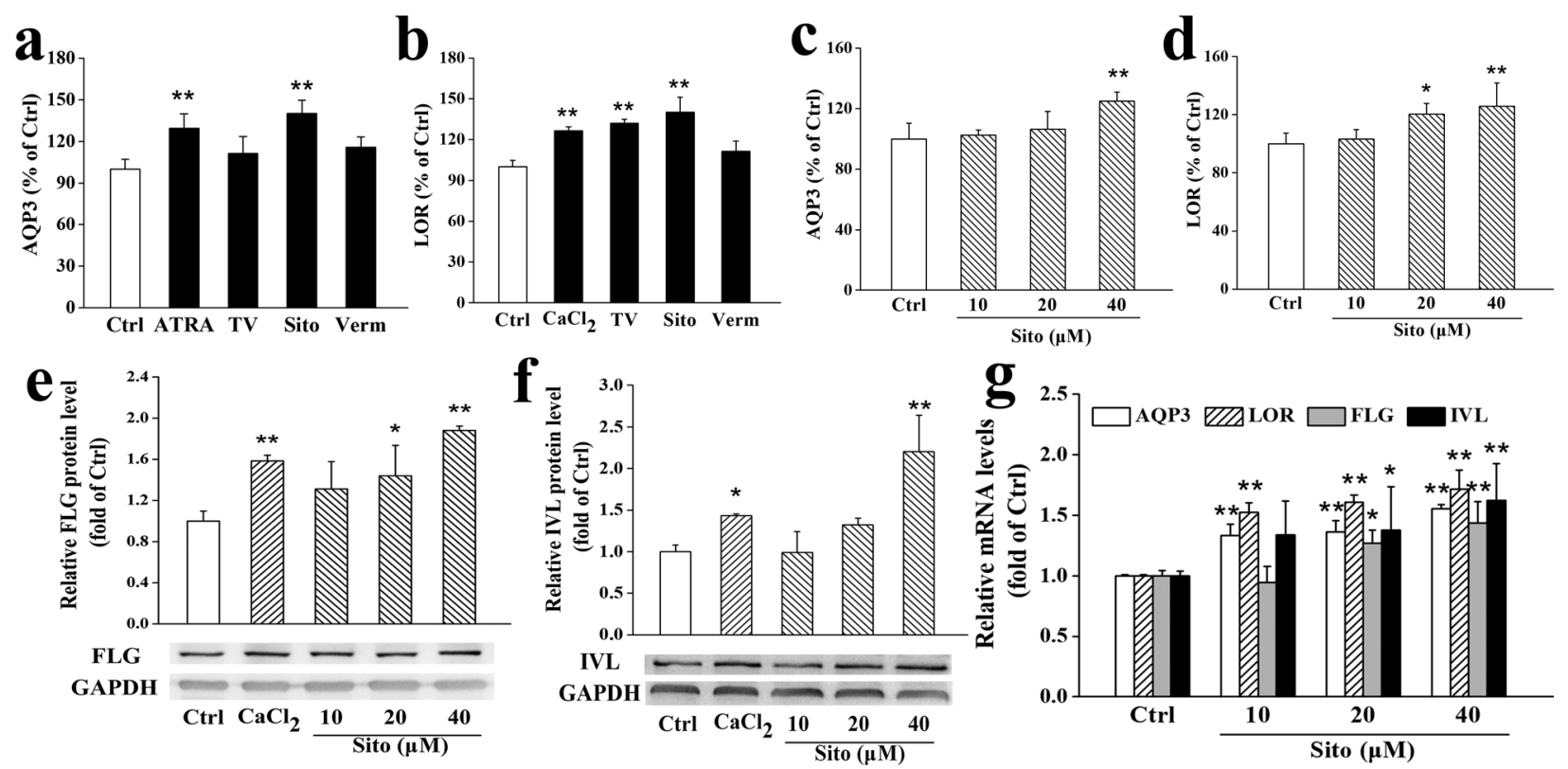

Figure 3 - Effects of compounds on the expression of AQP3, LOR, FLG and IVL in HaCaT. The protein expression of AQP3 (a, c) and LOR (b, d) was measured by ELISA. The protein expression of FLG (e) and IVL (f) was measured by western blot. The mRNA expression of AQP3, LOR, FLG and IVL (g) was measured by qRT-PCR. * $P<0.05$ and $* * P<0.01$ vs. Ctrl group.

of COL-I, MMP-1 and ROS in a does-dependent manner (Fig. 4d-f).

For further explaining the specific role of Verm against skin aging, its effect on the activation of MAPK signaling (ERK, JNK and p38 MAPK) was examined by western blot. The phosphorylation of ERK, JNK and p38 MAPK heightened in $\mathrm{H}_{2} \mathrm{O}_{2}$-induced HDF (Fig. 5). Verm obviously suppressed the phosphorylation of ERK and JNK in a does-dependently manner (Fig. 5a, b), and the phosphorylation of p38 (p-p38) was also attenuated as the concentration of Verm reached $20 \mu \mathrm{M}$ (Fig. 5c).

\section{DISCUSSION}

Dryness and wrinkles are typical features of skin aging. Thereby, materials with moisturizing and anti-wrinkling activities are potential candidates to anti-aging ingredients in skincare formulations. Sito generally exists in human diet as well as many medicinal plants and possesses anti-cancer, antiinflammatory and analgesic activities (Lomenick et al. 2015, Villaseñor et al. 2002). Verm is a main characteristic component in $T$. vermicularis with physiological activities of anti-inflammatory and antipyretic (Guo et al. 2011, Crawford 2015). Sito and Verm are typical components of TV which showed anti-aging effect. In this study, their activities on moisturizing and anti-wrinkling were investigated within skin cells and the mechanisms of protection were further discussed.

HA functions crucially in moisture holding of the skin, in which the metabolism in mammals is directly regulated by hyaluronic acid synthases (HAS1-3) and hyaluronidases (HYAL1-3) (Lee et al. 2016, Averbeck et al. 2007, Itano and Kimata 2002). That Sito could promote HA secretion and enhance HAS1-3 expression significantly revealed its probable moisturizing activity through promoting the biosynthesis of HA chains and thus raising the HA level. In addition, epidermal barrier function is another important regulation for skin moisture, as it can prevent the moisture from transepidermal loss (Tončić et al. 2018, Chaudhuri and Bojanowski 2017, Li et al. 2010). Since Sito was 

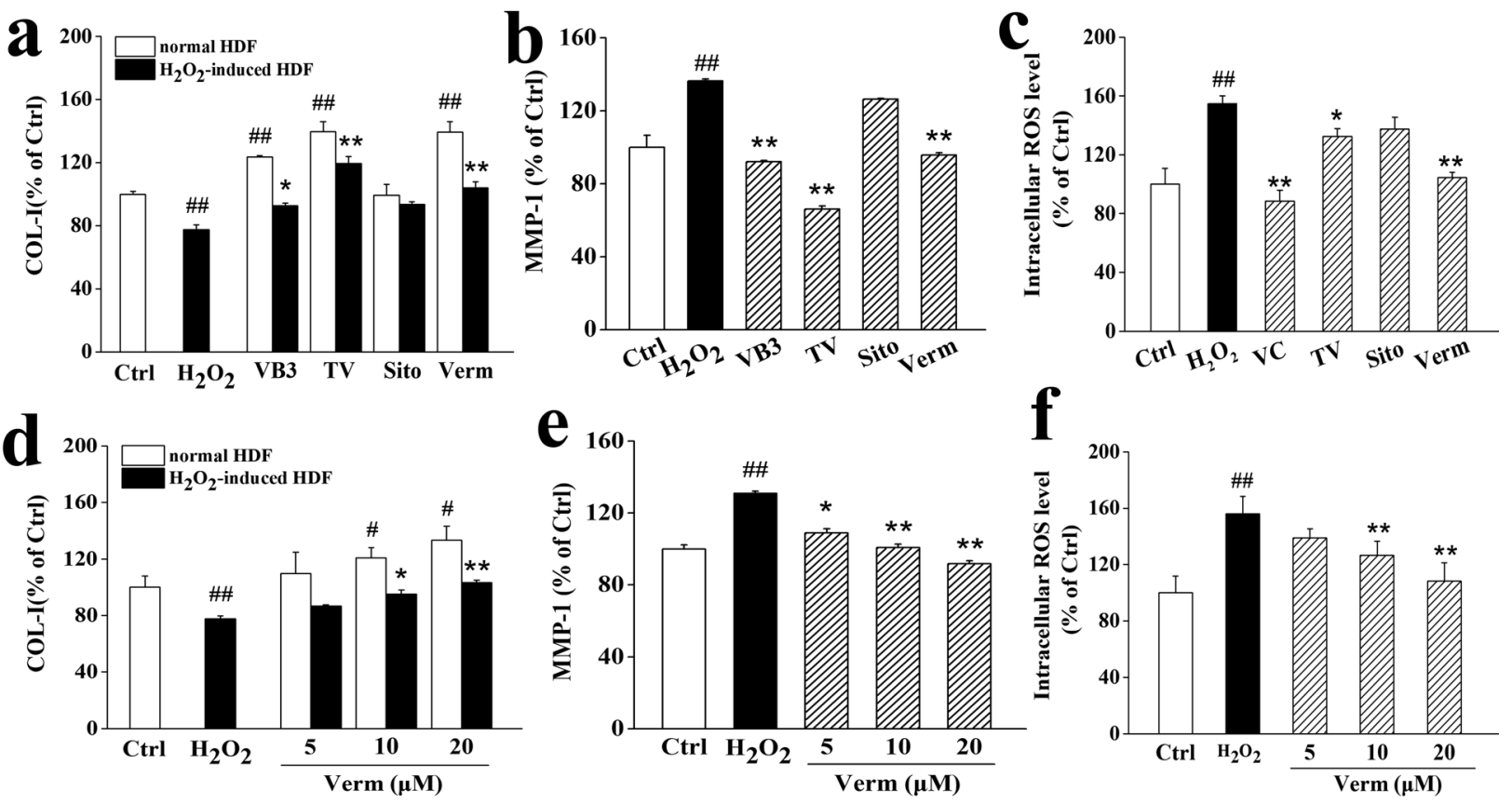

Figure 4 - Effects of compounds on COL-I secretion, MMP-1 production and ROS level in $\mathrm{H}_{2} \mathrm{O}_{2}$-induced HDF. COL-I secretion (a, d) and MMP-1 production (b, e) were measured by ELISA. The level of intracellular ROS (c, f) was measured using a fluorometric ROS assay kit. ${ }^{\#} P<0.05$ and ${ }^{\# \#} P<0.01$ vs. Ctrl group. ${ }^{*} P<0.05$ and $* * P<0.01$ vs. $\mathrm{H}_{2} \mathrm{O}_{2}$ group.

found to enhance the expression levels of water channel protein (AQP3) and the components of cornified envelop (LOR, FLG and IVL) in HaCaT, it could also lock skin moisture through promoting skin barrier function. The dual effect enabled Sito to be an active ingredient for dryness relief, which outperformed Verm. The results were consistent with the previous report of phytosterols being used as cosmetic additives to retain moisture and deter skin aging (Folmer 2003).

COL-I loss can induce fragility of collagen fibers, which further results in the formation of skin wrinkles, one of its major cause is MMP1 overexpression. Oxidative stress has been recognized as an important molecular mechanism of skin aging, and it was reported that ROS-activated MAPK signaling could stimulate the expression of MMP-1 in HDF (Lephart 2016, Noh et al. 2016, Lu et al. 2017, Sun et al. 2017). In this study, Verm was found to increase COL-I level and inhibit MMPloverexpression so as to perform anti-wrinkling effect that Sito could not realize. Moreover, our results suggested that indeed Verm could attenuate the $\mathrm{H}_{2} \mathrm{O}_{2}$-induced overproduction of ROS, which further supported the former findings that phenolic compounds with activities in antioxidation, collagen synthesis promotion, as well as collagen degradation inhibition effected skin anti-aging (Kammeyer and Luiten 2015, Svobodová et al. 2003, Fisher et al. 2002).

ERK, JNK and p38 MAPK are key members of MAPK signaling pathway. As reported before, phosphorylation of ERK and JNK could mediate the activation of c-fos and/or c-jun; then, activated c-fos and c-jun would constitute AP-1 the transcription factor that further regulated the expression of MMP-1 (Sun et al. 2017). Since experimental results in this work revealed the suppressed phosphorylation of ERK and JNK by Verm in $\mathrm{H}_{2} \mathrm{O}_{2}$-induced HDF, Verm was proved an anti-aging agent that prevented COL-I loss via inhibiting the expression of MMP-1 in the way of reducing intracellular ROS level and suppressing the MAPK signaling activation. Actually, 

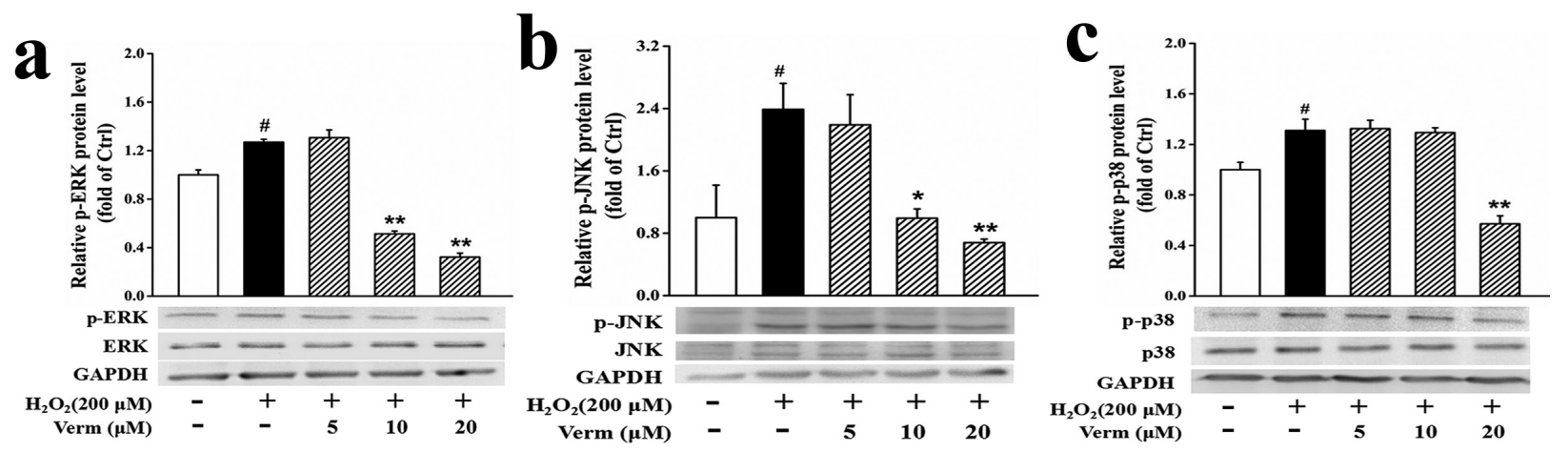

Figure 5 - Effect of Verm on the activation of MAPK signaling in $\mathrm{H}_{2} \mathrm{O}_{2}$-induced HDF. The phosphorylation levels of ERK (a), JNK (b) and p38 (c) were examined by western blot. ${ }^{\#} P<0.05$ vs. Ctrl group. ${ }^{*} P<0.05$ and $* * P<0.01$ vs. $\mathrm{H}_{2} \mathrm{O}_{2}$ group.

activation of transforming growth factor-beta (TGF- $\beta$ ) signaling pathway was also proposed as another anti-aging strategy, for it could upregulate the collagen expression (Gao et al. 2018, Park et al. 2018). Verm's effects on this pathway, however, are open to further investigation.

In conclusion, $\beta$-sitosterol and vermicularin are two active compounds preventing skin aging. Sito could promote the biosynthesis of HA and enhance the skin barrier function. This dual effect enables Sito to be an active compound for skin moisturing. While, Verm was able to prevent COL-I loss via antioxidation and collagen degradation inhibition so as to perform anti-wrinkling effect. Our findings contributes to the development of $\beta$-sitosterol and vermicularin as anti-aging ingredients for application in skincare products, in addition, the research may provide reference for future studies on the bioactivities of raw material containing these compounds.

\section{ACKNOWLEDGMENTS}

This study was funded by Shanghai Baoshan Government Industry University Institute collaboration (No. 17-C-1), the Fundamental Research Funds for the Central Universities (No. 22221818014) and Shanghai Inoherb limited company.

\section{AUTHOR CONTRIBUTIONS}

Haiyuan Yu and Yanhua Lu originally designed the experiments. Minhua Hong and Dan Liu provided Thamnolia vermicularis (Sw.) Ach. extract and identified the components. Haiyuan $\mathrm{Yu}$ and Xueqing Shen performed the experiments. All authors discussed the results. Haiyuan Yu wrote the manuscript.

\section{REFERENCES}

AVERBECK M, GEBHARDT CA, VOIGT S, BEILHARZ S, ANDEREGG U, TERMEER CC, SLEEMAN JP AND SIMON JC. 2007. Differential regulation of hyaluronan metabolism in the epidermal and dermal compartments of human skin by UVB irradiation. J Invest Dermatol 127: 687-697.

BELLEMÈRE G, VON STETTEN O AND ODDOS T. 2008. Retinoic acid increases aquaporin 3 expression in normal human skin. J Invest Dermatol 128: 542-548.

CHAUDHURI RK AND BOJANOWSKI K. 2017. Improvement of hydration and epidermal barrier function in human skin by a novel compound isosorbide dicaprylate. Int J Cosmet Sci 39: 518-526.

CHEN AC AND DAMIAN DL. 2014. Nicotinamide and the skin. Australas J Dermatol 55: 169-175.

CHEN D, ZHANG Z, JIANG Y, FANG Z AND CONG F. 2017. Anti-aging Effects of Glacial Water and Thamnolia vermicularis Extract on Human Dermal Fibroblasts. Nat Prod Res Dev 3: 469-474.

CONTET-AUDONNEAU JL, JEANMAIRE C AND PAULY G. 1999. A histological study of human wrinkle structures: comparison between sun-exposed areas of the 
face, with or without wrinkles, and sun-protected areas. Br J Dermatol 140(6): 1038-1047.

CRAWFORD SD. 2015. Lichens used in traditional medicine. In: Rankovie B (Ed), Lichen Secondary Metabolites: Bioactive Properties and Pharmaceutical Potential, Springer, Switzerland, p. 27-80.

FARAGE MA, MILLER KW, ELSNER P AND MAIBACH HI. 2008. Intrinsic and extrinsic factors in skin ageing: a review. Int J Cosmet Sci 30(2): 87-95.

FISHER GJ, KANG S, VARANI J, BATA-CSORGO Z, WAN Y, DATTA S AND VOORHEES JJ. 2002. Mechanisms of photoaging and chronological skin aging. Arch Dermatol 138(11): 1462-1470.

FOLMER BM. 2003. Sterol surfactants: from synthesis to applications. Adv Colloid Interface Sci 103(2): 99-119.

FREITAS-RODRÍGUEZ S, FOLGUERAS AR AND LÓPEZ-OTÍN C. 2017. The role of matrix metalloproteinases in aging: Tissue remodeling and beyond. Biochim Biophys Acta 1864(11 pt A): 2015-2025.

GAO W, WANG YS, HWANG E, LIN P, BAE J, SEO SA, YAN Z AND YI TH. 2018. Rubus idaeus L. (red raspberry) blocks UVB-induced MMP production and promotes type I procollagen synthesis via inhibition of MAPK/AP-1, NF- $\kappa \beta$ and stimulation of TGF- $\beta /$ Smad, Nrf2 in normal human dermal fibroblasts. J Photochem Photobiol B 185: 241-253.

GUO J, LI ZL, WANG AL, LIU XQ, WANG J, GUO X, JING YK AND HUA HM. 2011. Three new phenolic compounds from the lichen Thamnolia vermicularis and their antiproliferative effects in prostate cancer cells. Planta Med 77(18): 2042-2046.

HASHIZUME H. 2004. Skin aging and dry skin. J Dermatol 31(8): 603-609.

ITANO N AND KIMATA K. 2002. Mammalian hyaluronan synthases. Iubmb Life 54(4): 195-199.

JUHÁSZ ML, LEVIN MK AND MARMUR ES. 2018. The use of natural ingredients in innovative Korean cosmeceuticals. J Cosmet Dermatol 17(3): 305-312.

KAMMEYER A AND LUITEN RM. 2015. Oxidation events and skin aging. Ageing Res Rev 21: 16-29.

KIM YJ, CHOI MJ, BAK DH, LEE BC, KO EJ, AHN GR, AHN SW, KIM MJ, NA J AND KIM BJ. 2018. Topical administration of EGF suppresses immune response and protects skin barrier in DNCB-induced atopic dermatitis in NC/Nga mice. Sci Rep 8: 11895.

LEE DH, OH JHAND CHUNG JH. 2016. Glycosaminoglycan and proteoglycan in skin aging. J Dermatol Sci 83(3): 174181.

LEPHART ED. 2016. Skin aging and oxidative stress: Equol's anti-aging effects via biochemical and molecular mechanisms. Ageing Res Rev 31: 36-54.

LI J, TANG H, HU X, CHEN M AND XIE H. 2010. Aquaporin-3 gene and protein expression in sun-protected human skin decreases with skin ageing. Australas J Dermatol 51(2): 106-112.

LOMENICK B, SHI H, HUANG J AND CHEN C. 2015. Identification and Characterization of $\beta$-Sitosterol Target Proteins. Bioorg Med Chem Lett 25(21): 4976-4979.

LU J, HOU H, FAN Y, YANG T AND LI B. 2017. Identification of MMP-1 inhibitory peptides from cod skin gelatin hydrolysates and the inhibition mechanism by MAPK signaling pathway. J Funct Foods 33: 251-260.

LUO H, REN M, LIM KM, KOH YJ, WANG LS AND HUR JS. 2006. Antioxidative Activity of Lichen Thamnolia vermicularis in vitro. Mycobiology 34(3): 124-127.

MA ZM AND CHEN XR. 2001. Chemical constituents of Thamnolia vermicularis. Lishizhen Med Mater Med Res 12: 872-873.

NOH EM ET AL. 2016. Skin aging-dependent activation of the PI3K signaling pathway via downregulation of PTEN increases intracellular ROS in Human Dermal Fibroblasts. Oxid Med Cell Longev 2016: 6354261.

PAPAKONSTANTINOU E, ROTH M AND KARAKIULAKIS G. 2012. Hyaluronic acid: A key molecule in skin aging. Dermatoendocrinol 4(3): 253-258.

PARK B, HWANG E, SEO SA, CHO JG, YANG JE AND YI TH. 2018. Eucalyptus globulus extract protects against UVB-induced photoaging by enhancing collagen synthesis via regulation of TGF- $\beta /$ Smad signals and attenuation of AP-1. Arch Biochem Biophys 637: 31-39.

PLEGUEZUELOS O AND KAPAS S. 2006. Differentiation of the HaCaT keratinocyte cell line: modulation by adrenomedullin. Br J Dermatol 154(4): 602-608.

SUN Z, PARK SY, HWANG E, ZHANG M, SEO SA, LIN P AND YI TH. 2017. Thymus vulgaris alleviates UVB irradiation induced skin damage via inhibition of MAPK/ AP-1 and activation of Nrf2-ARE antioxidant system. J Cell Mol Med 21(2): 336-348.

SVOBODOVÁ A, PSOTOVÁ J AND WALTEROVÁ D. 2003. Natural phenolics in the prevention of UV-induced skin damage. A review. Biomed Pap Med Fac Univ Palacky Olomouc Czech Repub 147(2): 137-145.

TOBIN DJ. 2017. Introduction to skin aging. J Tissue Viability 26(1): 37-46.

TONČIĆ RJ, KEZIĆ S, HADŽAVDIĆ SL AND MARINOVIĆ B. 2018. Skin barrier and dry skin in the mature patient. Clin Dermatol 36(2): 109-115.

VILLASEÑOR IM, ANGELADA J, CANLAS AP AND ECHEGOYEN D. 2002. Bioactivity studies on betasitosterol and its glucoside. Phytother Res 16(5): 417-421.

WEN SY, CHEN JY, WENG YS, ANEJA R, CHEN CJ, HUANG CY AND KUO WW. 2017. Galangin suppresses $\mathrm{H}_{2} \mathrm{O}_{2}$-induced aging in human dermal fibroblasts. Environ Toxicol 32(12): 2419-2427.

ZHOU Y, DONG Y, XU QG, ZHU SY, TIAN SL, HUO JJ, HAO TT AND ZHU BW. 2014. Mussel oligopeptides 
protect human fibroblasts from hydrogen peroxide $\left(\mathrm{H}_{2} \mathrm{O}_{2}\right)$ induced premature senescence. Arch Gerontol Geriatr 58(2): 293-299.

ZOUBOULIS CC AND MAKRANTONAKI E. 2011. Clinical aspects and molecular diagnostics of skin aging. Clin Dermatol 29(1): 3-14.

\section{SUPPLEMENTARY MATERIAL}

Figure S1 - HPLC chromatographic profile of T. vermicularis extract (a) and $\beta$-sitosterol standard (b). HPLC condition: Agilent ZORBAX Eclipse XDB-C18 column $(4.6 \times 250$ mm, $5 \mu \mathrm{m})$, DAD G1315B Detector, G1311QuatPump, mobile phase methanol/water $(90: 10, \mathrm{v} / \mathrm{v})$, flow rate $1.0 \mathrm{~mL} /$ min, injection volume $20 \mu \mathrm{L}$, detection wavelength $210 \mathrm{~nm}$, column temperature $25^{\circ} \mathrm{C}$.

Figure S2 - MS profile of $\beta$-sitosterol ((+) ESI-TOF: 437.2 $\mathrm{M}+\mathrm{Na}^{+}$).

Figure S3 - MS profile of vermicularin ((-) ESI-TOF: 375.1 $\mathrm{M}-\mathrm{H}^{+}$).

Figure $\mathbf{S 4}-{ }^{1} \mathrm{H}$ NMR spectrum of vermicularin in $\mathrm{CDCl}_{3}(400$ $\mathrm{Hz}$ ). 